\title{
Impact and cost-benefit analysis: a unifying approach
}

\author{
Pasquale Lucio Scandizzo* (1)
}

${ }^{*}$ Correspondence:

Lucio.scandizzo@gmail.com

Università Degli Studi Di

Roma "Tor Vergata", Rome, Italy

\begin{abstract}
This paper presents a methodology to integrate cost-benefit analysis and SAM-CGEbased impact evaluation. While the two types of analysis have developed in parallel and without a clear connection, there is growing consensus that the two approaches should be integrated for complex investment projects, since their economic evaluation cannot rely solely on the partial equilibrium assumptions of cost-benefit (CB) analysis. Unlike CB analysis, impact evaluation looks at the economy as a complete system of interdependent components (industries, households, investors, government, importers, exporters). By integrating project accounting into a SAM-CGE framework, the methodology developed presents several properties that make it fit to the purpose of providing a reliable assessment of project contribution to the economy.
\end{abstract}

Keywords: Social accounting matrix (SAM), Computable general equilibrium models (CGE), Project, Evaluation, Impact analysis, Cost, Benefit analysis

JEL Classification: D57, D58, D62, E17, F35, O22

\section{Background}

A social accounting matrix (SAM) is an analytical construct that brings together the material input output matrix originally conceived by Leontief, with a consistent framework of transactions across production sectors, factors of production and various classes of economic agents. In the form that has become more popular and was developed first by Stone's research team in Cambridge, the SAM is the basis of modern national accounting and records transactions across activities, production factors, and the main institutional agents that constitute a modern market economy, namely households, enterprises, government, the financial and the international trade sector. As for the input-output, but in more integrated and value-based fashion, a SAM collects data on inflows and outflows of services by recording receipts and payments using the double accounting principle in a mutually consistent form. By convention, each column of a SAM thus records payments from that account to each other account, while each row records receipts to a specific account from each other account, with total receipts being equal to total expenditures. For this reason, the columns reporting production activities outlays can be interpreted as production processes, whose costs, including factor payments, equal in aggregate the value of production. At the same time, the corresponding

(c) The Author(s) 2021. This article is licensed under a Creative Commons Attribution 4.0 International License, which permits use, sharing adaptation, distribution and reproduction in any medium or format, as long as you give appropriate credit to the original author(s) and the source, provide a link to the Creative Commons licence, and indicate if changes were made. The images or other third party material in this article are included in the article's Creative Commons licence, unless indicated otherwise in a credit line to the material. If material is not included in the article's Creative Commons licence and your intended use is not permitted by statutory regulation or exceeds the permitted use, you will need to obtain permission directly from the copyright holder. To view a copy of this licence, visit http://creativeco mmons.org/licenses/by/4.0/ 
rows can be interpreted as the revenues of each activity from all other activities. The SAM records value added formation by accounting for payments from activities to primary production factors (capital and labor) and to the government in the form of indirect taxation. The SAM also accounts for income formation by recording payments from factors of production (value added) to households, government and other institutions, including the financial and the foreign sector, and by accounting for other transactions, including direct taxes, subsidies, interest payments and various types of transfers across institutions. The SAM concept and practice is at the base of the UN national account system (SNA), and in more recent years it has been extended to include environmental flows, such as carbon emissions and ecosystem services of various sort (BurthooBarah et al. 2019; Scandizzo and Cufari 2019; Scandizzo and Ferrarese 2015).

While the SAM has been often utilized to evaluate the indirect effects of capital expenditures from investment projects as a demand shock (Scandizzo and Ferrarese 2015; Debowicz et al. 2013), its use to assess the impact of the investment beyond the activation effects of the construction period, has been limited. The theory and practice of project evaluation has also typically neglected the fact that, while in the construction period a project may be considered as part of the capital formation account, after the construction period, the project is generally a production activity, which is linked to sectors, factors and institutions by a series of transactions that can be accounted for, using the same principles, industrial classification and balancing of all other activities represented in the SAM. For example, the increased demand generated by public investment in a new road during the construction period can be measured as a vector of purchases of capital goods, in analogy and as an implicit part of the investment (capital formation) vector in the SAM. Once completed, however, the road becomes a service producing activity that not only generates increased demand for inputs, but also contributes to revenue formation, increase consumer surpluses and spill over the economy thereby increasing economic activity in the rest of the economy. An investment project, in particular, is characterized by a cash flow, for each year or project life, that can be split into a series of costs and a series of revenues and, as such, conveniently represented in a specific column and row of a SAM. This representation not only provides a convenient way to represent a project in a SAM, but also suggests that SAM production activities can be seen as sets of investment projects at various stages of implementation and are thus subject to variations over time due to the overlapping of projects of different generations. In turn, this twofold consideration on the role of projects as activities and of the activities as overlapping ongoing projects, indicates that a proper SAM accounting should not only aim at accounting for direct responses to final demand changes, but also for the variation of the patterns of transactions (i.e., changes in the SAM coefficients) due to new projects and technologies.

Following Stone's original interpretation (Stone 1952), SAM accounts and coefficients can be considered special cases, respectively, of a transaction and a response matrix for an economy. The response matrix can be more or less complex and may coincide with a linear approximation of a full-fledged computable general equilibrium model (Perali and Scandizzo 2018). In the case of an investment project, therefore, while the project cash flow can be directly incorporated in a transaction SAM, its translation into a column and row vector of coefficients require a series of assumptions on the technology and the 
behavior of the economic agents involved. In the simplest case, the response matrix is a matrix of input output coefficients for the production activities, and of expenditure shares for the behavior of the institutions (households, government, etc.). In the case of a CGE model, the project transaction column contains, for each period of project life, the project payments to the factors of production (including the project net revenues to capital), as well as to activities and institutions. The response (coefficient) column instead in the simplest case embeds the hypothesis that project outlays are fixed proportions of its total cost. Similarly, the project transaction row contains the revenues and possibly the external effects paid to the project by production activities, institutions and the financial sector. For these stakeholders the payments made to project represent costs for goods or services provided by the project, so that in the response matrix, they are converted into coefficients, which in the simplest case are fixed proportions of total costs of their own production. As required for all SAM accounts, project rows and columns of the transaction matrix balance, since the project outlays, which include the net project revenues paid to capital, equal the project inflows or gross revenues with any financial gap filled by the capital formation (i.e., the financing) sector. For example, in the construction period, the outlays will consist of the construction costs, while the balancing inflows will be provided by payments from the capital formation accounts.

More generally, the rows and columns of the SAM as a transaction matrix can be reinterpreted as the twin entries of the cash flow account of an economy for a given period of time. For the production sectors, this means that revenues from product sales are recorded in the row entries and costs in the column entries. The difference between revenues and intermediate costs is value added. This can be considered a result of the production activity (the larger the better, ceteris paribus) and is the basis to compute all welfare measures including GDP. In turn, value added is recorded as a row entry in the accounts of factors of production. Here row entries represent incomes from employment while column entries document payments to factor owners, which in a market economy are households, firms and the government. For institutions, finally, row entries represent incomes from factor ownership, interests and dividends, or transfers of various kind, while column entries are expenditures for goods and services and savings (as purchases of financial assets). Rather than value added, however, the return to capital in the form of gross margins of production are recorded as the difference between sector revenues and sector costs (including cost of intermediates and cost of labor) and are credited to the account of capital as a factor of production.

In sum, while the general practice in input output and SAM-based model has been to consider an investment project as a vector of expenditure shocks, the proper way to analyze it is as a special form of an activity, with its own input output parameters that evolve over time. This type of activity is characterized by a series of cash flows that change over time. At any point in time an investment project can thus be represented in the SAM as a column of cash outflows, including all capital and maintenance costs from intermediates and resulting value added, and as a row of cash inflows, including financing from the government and private savings during the construction phase, and revenues from increased production of goods and services during the operational phase. Since costs and revenues have to balance, financing from the capital formation sector, or directly from the government or other project sponsors must be recorded 
as one or more row entries in the years where cash outflows are larger than cash inflows (the "construction" period). Vice versa, once the project is operational and inflows become larger than outflows, returns can be credited to capital (as gross business margins) or institutions (government or households).

The benefits from the project, however, are not limited to the remuneration of capital, since other social benefits and costs may also be considered in the economic analysis.

\section{Methods}

\subsection{A SAM-based model for project evaluation}

Consider the social accounting matrix equation for a generic scenario:

$$
X=A X,
$$

where $X$ is an $n, 1$ vector of activity levels for productive sectors, and incomes for factors and institutions and $Q=I-A$, the SAM coefficient matrix.

We can consider an investment project as an additional activity and augment the size of the SAM by adding a column and a row of transactions corresponding, respectively, to the outlays and the receipts of the project cash flow. In order for the inflows and outflows to balance, this entails, in particular, accounting, among the receipts, for any financing flow and, among the expenditures, any profits distributed to factors of production and other stakeholders. We can then write two new equilibrium conditions for the situation "without" and "with project" SAM as:

$$
\begin{aligned}
& X_{s}=A_{s} X_{s}, \\
& X_{c}=A_{c} X_{c} .
\end{aligned}
$$

In (2a) and (2b), $A_{s}$ and $A_{c}$ are $n+1, n+1$, SAM matrices augmented of one column and one row to represent, respectively, the situation without and with the project. The matrix without the project $A_{s}$, in particular, can either contain an additional column and row of zeros, for the case of full project additionality, or the data of the cash flow of an alternative project as a counterfactual.

Subtracting Eq. (1) from Eqs. (2a) and (2b), we obtain, after some manipulation:

$$
\begin{aligned}
& X_{c}-X_{s}=A_{c}\left(X_{c}-X_{s}\right)+\left(A_{c}-A_{s}\right) X_{s}, \\
& X_{c}-X_{s}=A_{s}\left(X_{c}-X_{s}\right)+\left(A_{c}-A_{s}\right) X_{c} .
\end{aligned}
$$

As noted in the literature on structural decomposition (e.g., Rose and Casler 1996), the two expressions (3a) and (3b) signal an index number problem. In the remainder of this paper, we will assume that the differences between (3a) and (3b) are small enough that they can be ignored or otherwise solved by appropriately averaging the results obtained by separately applying the two equations (Koppany 2017, p. 619).

Both the $A_{s}$ and the $A_{c}$ matrix are singular, but we can decompose them into a nonsingular square submatrix of coefficients of endogenous variables and rectangular submatrices of coefficients of exogenous variables: 


$$
A_{i} X_{i}=\left[\begin{array}{cc}
A_{e e, i} & A_{e x, i} \\
A_{x e, i} & A_{x x, i}
\end{array}\right]\left[\begin{array}{l}
X_{e i} \\
X_{x i}
\end{array}\right] \quad \text { for } i=s, c .
$$

In (4) $X_{e i}$ and $X_{x i}$ are vectors, respectively, of endogenous and exogenous activity levels and $A_{e e, i}, A_{e x, i}, A_{x e, i}, A_{x x, i}$ corresponding submatrices from partitioning of $A_{i}$. Developing the expression, we can re-write (2) and (3) as follows:

$$
X_{e i}=A_{e e, i} X_{e i}+A_{e x, i} X_{x i} ; \quad i=s, c
$$

This expression identifies one part of the system $\left(A_{e x, i} X_{x i}\right)$ as a vector of exogenous demand levels and one part $\left(\left(I-A_{e e, i}\right) X_{e i}\right)$ as a corresponding vector of endogenous supply levels necessary to satisfy the direct and indirect demand generated by the exogenous demand levels.

Subtracting the endogenous vector without the project from the one with the project, we obtain:

$$
X_{e c}-X_{e s}=A_{e e, c}\left(X_{e c}-X_{e s}\right)+\left(A_{e e, c}-A_{e e, s}\right) X_{e s}+A_{e x, c}\left(X_{x c}-X_{x s}\right)+\left(A_{e x, c}-A_{e x, s}\right) X_{x s} .
$$

More synthetically, expression (6) can be re-written in difference notations as:

$$
\Delta X_{e}=A_{e e, c} \Delta X_{e}+\left(\Delta A_{e e}\right) X_{e s}+A_{e x, c} \Delta X_{x}+\Delta A_{e x} X_{x s} .
$$

Solving for the endogenous variables, we obtain:

$$
\Delta X_{e}=\left(I-A_{e e, c}\right)^{-1}\left[A_{e x, c} \Delta X_{x}+\left(\Delta A_{e e}\right) X_{e s}+\left(\Delta A_{e x}\right) X_{x s}\right] .
$$

Expression (8) indicates that the variation of the endogenous variables of the model may be the consequence of three different shocks, all filtered through the matrix of multipliers of the endogenous sectors: (i) the autonomous variation of the exogenous variables (capital formation, exports or a specific vector of project expenditures); (ii) the variation of the SAM coefficient submatrix of the transactions within the endogenous accounts, and (iii) the variation of the SAM submatrix of the transactions between the endogenous and the exogenous accounts. Intuitively, the exogenous activities increases aggregate demand through the value chains quantified in the SAM, but may also introduce technological change, and induce a new pattern of transactions, boost or reduce existing connections and create new ones.

If one of the exogenous accounts is a specific investment project, in particular, consider the exogenous variation measured by the project cash flow over a time horizon $t=0,1, \ldots . . T$ and the changes in the SAM coefficients due to the changes of the project cash flow every year.

Indicating with the $t$ subscript the time, the term $A_{e x, c, t} \Delta X_{x, t}=A_{e x, c, t}\left(X_{x c, t}-X_{x s, t}\right)$ is the increase in project expenditure in the $t$ th year, while $\left(\Delta A_{e x}^{t}\right) X_{x s}^{t}$, is the change induced by the project into the counterfactual SAM matrix of the same period without the project. With no competing alternative $\left(X_{x s, t}=0\right)$, we have: $A_{e x, c, t} \Delta X_{x, t}=A_{e x, c, t} X_{x c, t}$, i.e., the project cash flow. This includes, as all columns of the SAM, the demand increases (with respect to the situation without the project) generated by the expenditures of the project with respect to all sectors. These expenditures include both costs and net benefits of the project such as the payments made to project stakeholders as for example 
the net margins paid to capital and the other net benefits, accounted in gross terms in a corresponding row of the SAM. The term $\left(\Delta A_{\text {ext }}\right) X_{x t}=\left(A_{\text {ext }+1}-A_{\text {ext }}\right) X_{x s}^{t}$ represents the structural impact of the technology embodied in the project. This impact may be due to different project requirements in terms of use of intermediate inputs and value added in comparison to existing technologies. Project impact is thus evaluated as the sum of two components, one depending on the change in the scale of the cash flow, and one depending on the change of the weights of the different items of the project transaction vector in a new SAM updated to account for the transactions introduced by each phase of the project.

The present value at rate of discount $r$ of project impact can be directly derived from Eq. (8):

$$
\sum_{t=0}^{T} \frac{\Delta X_{e t}}{(1+r)^{t}}=\sum_{t=0}^{T} \frac{1}{(1+r)^{t}}\left(I-A_{e e, t+1}\right)^{-1}\left[A_{e x, t+1} \Delta X_{x t}+\left(\Delta A_{e e t}\right) X_{e t}+\left(\Delta A_{e x t}\right) X_{x t}\right] .
$$

However, $A_{e e, t+1}$ will approximately remain constant if the project is small enough, and $\Delta A_{\text {eet }} \cong 0$, so that expression (9) can be approximated on the basis of the initial SAM for the endogenous accounts:

$$
\sum_{t=0}^{T} \frac{\Delta X_{e t}}{(1+r)^{t}}=\left(I-A_{e e}\right)^{-1} \sum_{t=0}^{T} \frac{1}{(1+r)^{t}}\left[A_{e x, t+1} \Delta X_{x t}+\left(\Delta A_{e x t}\right) X_{x t}\right] .
$$

Expression (10) allows to estimate the present value of project impact using a single SAM and its variations as the direct and indirect effects of the present values of the project cash flows. In turn these are defined as the sum of two components: (i) the yearly project outlays for a given structure of the interdependencies between the project and the rest of the economy, and (ii) the yearly increases in the same outlays due to the variation of these interdependencies brought about by the changes of project outlays over time.

\section{Results}

\subsection{Building a project SAM}

In the theory of cost-benefit analysis, actual transactions in the form of revenues and expenditures at market prices are associated with the so-called "financial analysis", which has the purpose to evaluate projects from the point of view of a private subject. In the "economic analysis", instead, the basis to compute benefits and costs are no longer actual transactions at market prices, but virtual transactions that reflect what consumers or producers gain from market exchanges and other project effects, but not necessarily pay for them. Two typical concepts used to quantify these values are the well-known constructs of consumer and producer surplus.

While definitions can be made more precise by a better specified theoretical context, both consumers and producers surplus have a long history in economics as their definition and initial use is due to Marshall (1890), one of the founding fathers of microeconomic theory. Consumer surplus can be defined as the excess of willingness to pay for a good or service, compared to what consumers actually pay, while 
producer surplus can be similarly defined as the excess of the price received compared to producers' willingness to accept. In both cases, therefore, a measure of the difference between a virtual transaction and an actual one is used as a monetary measure of a real gain. While an increase in household income is matched by an increase in consumer expenditure and/or savings, an increase in consumer surplus does not apparently result in an increase in transactions. However, as shown by Weitzman (1988), real income, calculated with an appropriate price deflator (a Laspeyres index in case of homothetic preferences), is essentially equivalent to consumer surplus. This implies that any increase in consumer surplus is equivalent to the sum of the increase in income at baseline prices plus a term (of a second order of magnitude) reflecting the fact that real income is also larger because of as concomitant favorable change in relative prices. For example, suppose that the project determines an increase in market supply of a particular good and this determines a corresponding increase in consumer expenditure. This larger expenditure in turn can be decomposed in a consumption saving (i.e., a gain in income) for the quantity consumed without the project (i.e., for those who already consume the good) plus an increase in expenditure due to the fall in price.

In addition to consumer and producers surplus, cost-benefit analysis also takes into account a number of other benefits and costs that are not translated into market transactions, either because they are not the result of market exchanges or because market exchanges do not reflect "true" social values. In other words, these two classes of project effects reflect the so-called "shadow prices", which differ from market prices of an amount reflecting the components of social values that for various reasons are not internalized by existing markets. Since the important work of Ronald Coase (1937), these externalities have been recognized as themselves corresponding to virtual (or potential) transactions.

Table 1 shows how benefits and costs of a project can be incorporated in the project row (project receipts) and columns (project outlays). The economic components of project receipts are: (i) revenues from project intermediates; (ii) revenues from consumer purchases; (iii) government subsidies; (iv) debt or equity financing, and (v) exports. The corresponding project costs are: (i) capital and operational costs; (ii) net margins (credited to capital); (iii) consumer incomes, credited to households; (iv) taxes; (v) interests and dividends, and (vi) imports. The project row and column at market prices balance since net margins, i.e., the difference between revenues and costs are included in the project SAM column as a cost for capital. In this way the two sums, respectively, of the column and the row entries for market transactions (the so-called "financial analysis" of the project) equal the project gross revenues, i.e., all receipts. In order to go from financial to economic analysis all the above variables must valued at shadow prices and conform, as indicated in Weitzman (1976), Eisner (1988) and Hartwick (1990) to the notion of Net National Product (NNP), i.e., to an ideal flow measurement of national wealth of a dynamic economy. They can thus also incorporate social welfare effects, externalities and natural capital (last three rows and columns in the matrix) for which market prices are not available (as in Banerjee et al. 2016). 


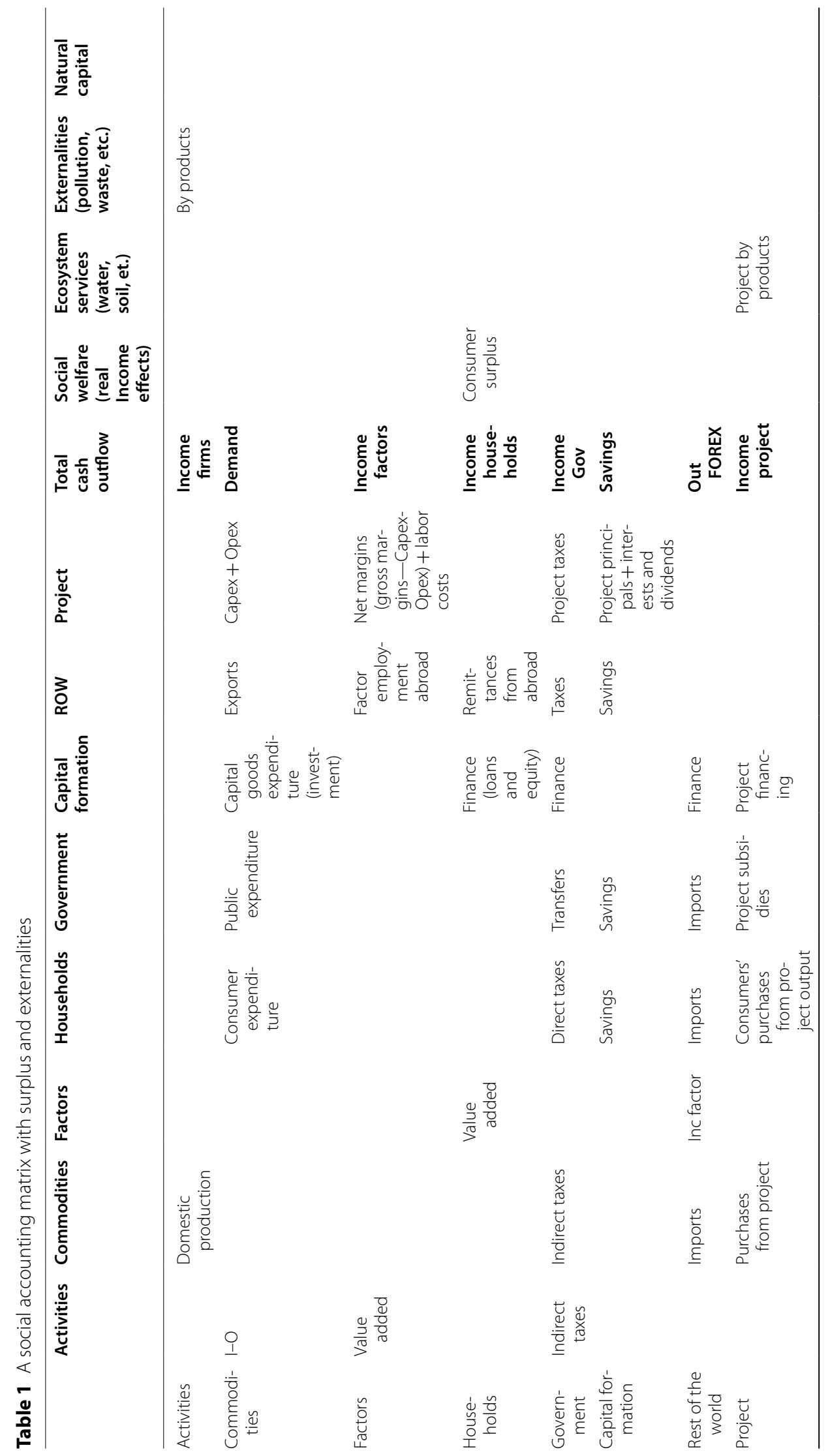




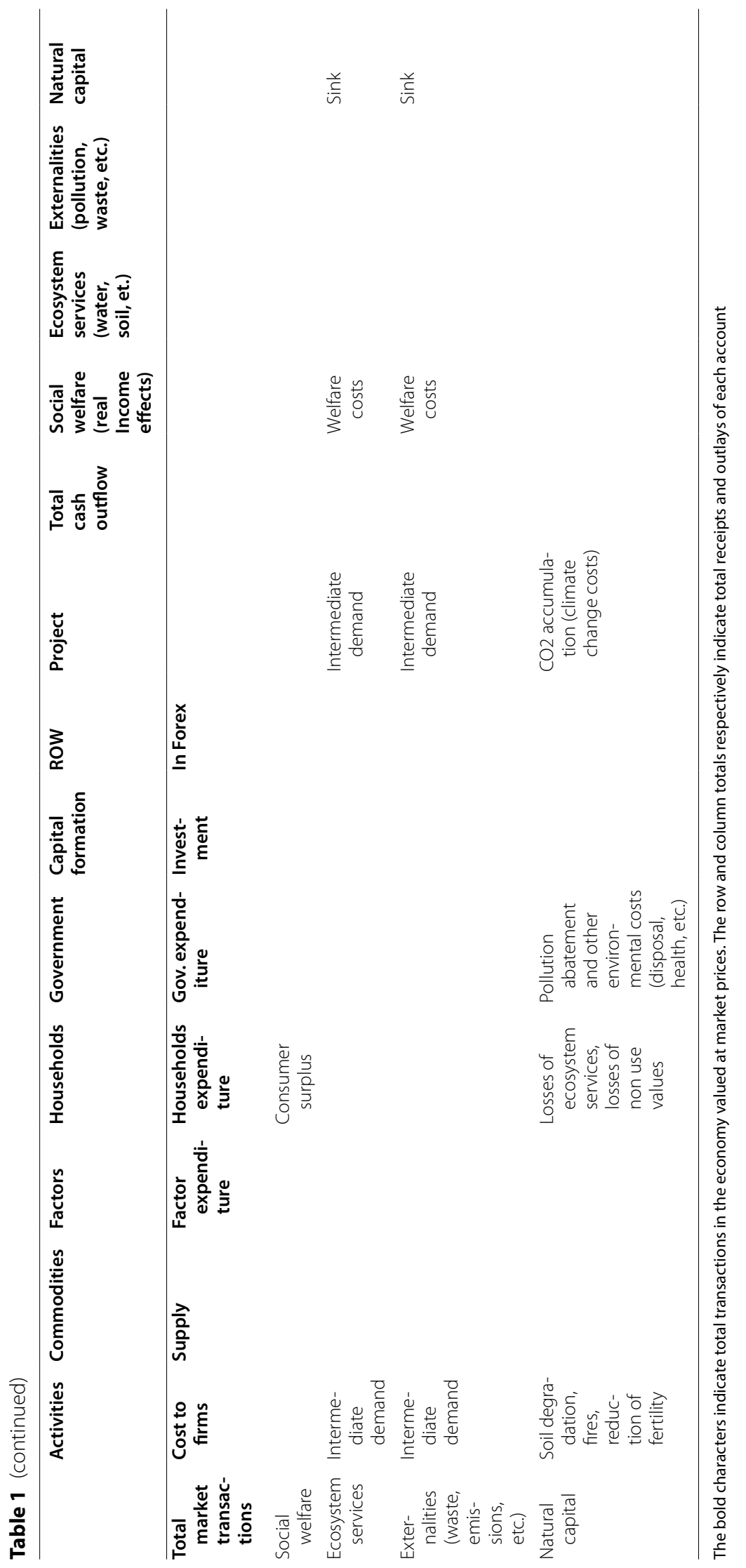


Table 2 SAM with project in the construction period $(t=0)$

\begin{tabular}{lrrrrrrrr}
\hline & Act & Value added & Households & Government & $\begin{array}{c}\text { Capital } \\
\text { formation }\end{array}$ & Row & Project & Total \\
\hline Act & 220 & 0 & 150 & 30 & 30 & 100 & 50 & 580 \\
Value added & 250 & 0 & 0 & 0 & 0 & 25 & 30 & 305 \\
Households & 0 & 280 & 40 & 45 & 0 & 0 & 0 & 365 \\
Government & 10 & 25 & 95 & 0 & 55 & 0 & 0 & 185 \\
Capital formation & 0 & 0 & 45 & 90 & 50 & 110 & 0 & 295 \\
ROW & 100 & 0 & 35 & 20 & 60 & 0 & 20 & 235 \\
Project & 0 & 0 & 0 & 0 & 100 & 0 & 0 & 100 \\
Total & 580 & 305 & 365 & 185 & 295 & 235 & 100 & \\
\hline
\end{tabular}

Table 3 SAM with project in the operational period $(t=1)$

\begin{tabular}{|c|c|c|c|c|c|c|c|c|}
\hline & Act & Value added & Households & Government & $\begin{array}{l}\text { Capital } \\
\text { formation }\end{array}$ & Row & Project & Total \\
\hline Act & 200 & 0 & 170 & 30 & 30 & 100 & 20 & 550 \\
\hline Value added & 195 & 0 & 10 & 0 & 0 & 70 & 200 & 475 \\
\hline Households & 0 & 410 & 40 & 60 & 50 & 0 & 0 & 560 \\
\hline Government & 10 & 30 & 170 & 0 & 70 & 0 & 0 & 280 \\
\hline Capital formation & 0 & 0 & 45 & 150 & 50 & 70 & 120 & 435 \\
\hline ROW & 100 & 30 & 100 & 30 & 215 & 0 & 25 & 500 \\
\hline Project & 45 & 5 & 25 & 10 & 20 & 260 & 0 & 365 \\
\hline Total & 550 & 475 & 560 & 280 & 435 & 500 & 365 & \\
\hline
\end{tabular}

\subsection{Economic analysis}

Tables 2 and 3 show an example of a social accounting matrix incorporating a project cash flow, respectively, in the construction period $(t=0)$, and in the operational period $(t=1)$, with the project cash flow being accounted for as an extra activity and/or institution in the SAM. The cash flow data in the construction period include only capital expenditure (capital goods produced by activities) in the account column and financing from capital formation in the account row. In the operational period, the project account column includes all project costs (capital replacement and operational costs), while the row account contains all project receipts. The value added account is credited in the project column of the payments to labor and capital, including the returns paid as net business margins to project sponsors. These payments amount to the sum of the inflows reported in the row minus all the costs (other than value added) reported in the column. As a consequence, the sum of the column and the sum of the row both amount to the gross revenue component of the project cash flow. In a more detailed account, with value added split between various types of production factors and a capital account, wages would be paid to different types of labor and the net margins from the project would be explicitly credited to capital. On the other hand, while net benefits depend on the return to capital, they also include the indirect effects on the economy which are credited to households, government or other accounts.

As Table 2 shows, in the construction period, the project is assumed to produce no revenues, while its costs are assumed to be 100 monetary units, with payments to activities, production factors (value added), and rest of the world (ROW). These 
costs are entirely financed from capital formation and give rise, to the extent that they mobilize unemployed resources, to value added increases through indirect effects. Revenues, on the other hand, are collected by the project as listed in the project row in Table 3. These revenues are collected from various stakeholders who purchase the goods or services provided by the project, including households and government. With no indirect effects, project net (financial) benefits would thus simply be the portion of value added credited to capital net of any charges due to user costs for maintenance.

Project financing is then repaid in the operational period with interests (120 monetary units versus the 100 units borrowed for construction). In this period (Table 3), the project is assumed to collect revenues equal to 365 units from all sectors and institutions, with intermediate costs of 20 units from domestic activities and 25 units from imports. The difference between project receipts of 365 and project intermediate costs of 45 is credited for 120 units to the capital formation account and for 200 units to the value added account and add to total project outlays, including loan repayment with interests accrued to capital formation. As a consequence, the value added account in the operation period is the sum of the project direct payments to production factors and indirect taxes to meet operational costs and of the returns to capital obtained from project revenues after paying for intermediate goods and capital formation. The capital formation expenditures include loan repayments, interests, capital depreciation (assumed to be 5\% per year) and any expenditure for replacement of capital goods.

The two transaction matrices in Tables 2 and 3 correspond to two coefficient matrices, whose difference is reported in Table 4.

Assuming as exogenous accounts, in addition to the project, capital formation and the rest of the world, we can now compute the project impact in both periods according to expressions (8) and (9).

Table 5 reports the values of the main SAM accounts affected by the project, while Table 6 compares outcome variables with project costs. Multiplier estimates from value added and, considering depreciation charges, for Net National Product (NNP) are around 1 for the construction period and around 1.5 for the operational period, where not only costs but also net revenues from the project are taken into account.

Table 4 Differences in the SAM coefficients between the operational and the construction period $\left(A_{t+1}-A_{t}\right)$

\begin{tabular}{lrrrrrrr}
\hline & Act & Value added & Households & Government & $\begin{array}{l}\text { Capital } \\
\text { Formation }\end{array}$ & Row & Project \\
\hline Act & -0.016 & 0.000 & -0.107 & -0.055 & -0.033 & -0.226 & -0.445 \\
Value added & -0.076 & 0.000 & 0.018 & 0.000 & 0.000 & 0.034 & 0.248 \\
Households & 0.000 & -0.055 & -0.038 & -0.029 & 0.115 & 0.000 & 0.000 \\
Government & 0.001 & -0.019 & 0.043 & 0.000 & -0.026 & 0.000 & 0.000 \\
Capital formation & 0.000 & 0.000 & -0.043 & 0.049 & -0.055 & -0.328 & 0.329 \\
ROW & 0.009 & 0.063 & 0.083 & -0.001 & 0.291 & 0.000 & -0.132 \\
Project & 0.082 & 0.011 & 0.045 & 0.036 & -0.293 & 0.520 & 0.000 \\
\hline
\end{tabular}


Table 5 Total project impact

\begin{tabular}{lccr}
\hline & Construction & Operations & PV \\
\hline Activities & 169.47 & 179.18 & 332.37 \\
Value added & 103.05 & 268.41 & 347.06 \\
Households'incomes & 117.72 & 273.31 & 366.19 \\
Government income & 42.01 & 103.18 & 135.81 \\
Total & 432.25 & 824.08 & 1181.42 \\
\hline
\end{tabular}

Table 6 Project performance indicators

\begin{tabular}{lllc}
\hline & Construction & Operation & $\begin{array}{l}\text { Present values } \\
\text { at 10\% discount }\end{array}$ \\
\hline Project costs & 100 & 245 & 322.73 \\
Value added increase & 103.05 & 378.36 & 447.02 \\
NNP increase & 97.9 & 359.45 & 424.67 \\
VA/costs & 1.03 & 1.54 & 1.39 \\
NNP/costs & 0.98 & 1.47 & 1.32 \\
\hline
\end{tabular}

\section{Discussion}

In this paper, I have presented a methodology to integrate cost-benefit analysis in the impact evaluation performed on the basis of social accounting principles (SAM or SAM-based models). The integration requires simply a recasting of the economic and/or financial data used in the discounted cash flow analysis in the format used in the SAM accounts and involves a simple reclassification of costs and revenues according to the statistical system used in the SAM (Eisner 1988). The methodology generalizes the use of multipliers to evaluate the short-term impact of investment projects, which is typically used alongside cost-benefit analysis, but without a clear relation with both its theoretical principles and practical applications. Unlike the simple multiplier method, by integrating project accounting in the SAM, it allows an exhaustive analysis of impact on revenues, costs and financing, thus providing a clear picture of the project contribution to both demand and supply both in the project construction and operational periods. By integrating in a consistent accounting framework value added formation and economic benefits and costs, this method also allows making full use of the information provided by the sector and the distributional details of investment cash flows through the entire project life.

Acknowledgements

Not applicable.

Authors' contributions

The author read and approved the final manuscript.

Funding

Funding for this research was received by OpenEconomics (www.openeconomics.eu).

Availability of data and materials

Not applicable. 


\section{Declarations}

Ethics approval and consent to participate

This research does not involve human subjects, human material, or human data.

\section{Consent for publication}

This manuscript does not include details, images, or videos relating to individual participants.

\section{Competing interests}

The author declares that he has no competing interests.

Received: 14 December 2020 Revised: 21 June 2021 Accepted: 26 June 2021

Published online: 07 July 2021

\section{References}

Banerjee O, Cicowiez M, Vargas R, Horridge J (2016) The SEEA-based integrated economic-environmental modelling framework: an illustration with Guatemala's Fuelwood/Forest Sector

Burthoo-Barah SB, Dawoonauth M, Scandizzo PL (2019) "Exploring the distributional impact of investment in the port sector on households in Mauritius: a social accounting matrix approach", Marine Policy, 2019. Elsevier, Amsterdam Coase R (1937) The nature of the firm. Economica 9:386-405

Debowicz D, Dorosh P, Haider HS et al (2013) A dsaggregated and macro-consistent social accounting matrix for Pakistan. Econ Struct 2:4

Hartwick JM (1990) Natural resources, national accounting and economic depreciation. J Public Econ 43:291-304 Eisner R (1988) Extended accounts for national income and product. J Econ Lit 26:1611-1684

Koppany K (2017) Estimating growth contributions by structural decomposition of input output tables. Acta Oeconomica. 67(4):605-642

Marshall A (1890) Principles of economics, vol 1. Macmillan, London

Perali F, Scandizzo PL (eds) (2018) The new generation of computable general equilibrium models. Springer, Berlin Rose A, Casler S (1996) Input-output structural decomposition analysis: a critical appraisal. Econ Syst Res 8(1):33-62 Scandizzo PL, Cufari D (2019) "Leveraging Natural Capital for Socially Inclusive Growth" in opportunities for environmentally healthy, inclusive, and resilient growth in Mexico's Yucatán Peninsula. World Bank, Washington, pp 65-82 Scandizzo PL, Ferrarese C (2015) Social accounting matrix a new estimation methodology. J Policy Model. 37:14-34 Stone R (1952) Simple transaction models, information and computing. Paper presented at a conference on Automatic Control, Cranfield, 1951. Rev Econ Stud. 19:67-84

Weitzman ML (1976) On the welfare significance of national product in a dynamic economy. Q J Econ 90:156-162 Weitzman ML (1988) Consumer's surplus as an exact approximation when prices are appropriately deflated. Q J Econ. 103(3):543-553

\section{Publisher's Note}

Springer Nature remains neutral with regard to jurisdictional claims in published maps and institutional affiliations.

\section{Submit your manuscript to a SpringerOpen ${ }^{\circ}$ journal and benefit from:}

- Convenient online submission

- Rigorous peer review

- Open access: articles freely available online

- High visibility within the field

- Retaining the copyright to your article

Submit your next manuscript at $\boldsymbol{\nabla}$ springeropen.com 